\title{
Using RV/LV ratio and cardiac biomarkers to define the risk of mortality from pulmonary embolism
}

\author{
Sümeyye AYÖZ ${ }^{1}$ (ID) \\ Serhat $\operatorname{EROL}^{1}(\mathrm{ID})$ \\ Melahat KUL ${ }^{2}(\mathrm{ID})$ \\ Aslıhan GÜRÜN \\ KAYA $^{1}($ ID) \\ Ayşegül GÜRSOY \\ $\mathrm{CPORUH}^{2}(\| \mathrm{D})$ \\ İsmail SAVAS ${ }^{1}$ (ID) \\ Ömür AYDIN ${ }^{1}$ \\ Akın KAYA ${ }^{\mathbf{1}}(\mathrm{ID})$
}

Cite this article as: Ayöz S, Erol S, Kul M, Gürün Kaya $A$, Gürsoy Çoruh A, Savaş $i$, et al. Using RV/LV ratio and cardiac biomarkers to define the risk of mortality from pulmonary embolism. Tuberk Toraks 2021;69(3):297306.

\section{Address for Correspondence (Yazışma Adresi)}

\section{Dr. Sümeyye AYÖZ}

Department of Chest Diseases,

Ankara University Faculty of Medicine,

ANKARA - TURKEY

e-mail: dr.sayoz@gmail.com

CCopyright 2021 by Tuberculosis and Thorax.

Available on-line at www.tuberktoraks.org.com
${ }^{1}$ Department of Chest Diseases, Ankara University Faculty of Medicine, Ankara, Turkey

${ }^{1}$ Ankara Üniversitesi Tıp Fakültesi, Göğüs Hastalıkları Anabilim Dalı, Ankara, Türkiye

2 Department of Radiology, Ankara University Faculty of Medicine, Ankara, Turkey

${ }^{2}$ Ankara Üniversitesi Tıp Fakültesi, Radyoloji Anabilim Dalı, Ankara, Türkiye

\section{ABSTRACT}

Using RV/LV ratio and cardiac biomarkers to define the risk of mortality from pulmonary embolism

Introduction: Acute pulmonary thromboembolism (PTE) is a common cause of cardiovascular mortality. Right ventricular (RV) dysfunction is the most important cause of mortality. Computed Tomography Pulmonary Angiography (CTPA) can detect right ventricular enlargement which is an indicator of RV dysfunction at the time of diagnosis. This study aimed to determine the parameters indicating RV dysfunction in CTPA and correlation of early mortality findings.

Materials and Methods: In this retrospective study, electronic files of patients diagnosed PTE with CTPA between January 2012 and December 2017 were evaluated. Measurements of heart chambers, IVC reflux, and IVS morphology were calculated. In-hospital mortality of the patients after acute PTE diagnosis was evaluated.

Results: There were 206 eligible patients. Among the evaluated radiological parameters, right atrium (RA) size $(p=0.002)$, PA size $(p=0.003)$, Ao size ( $p=$ $0.006)$, and the presence of IVC reflux $(p=0.001)$ were associated with mortality. No significant relationship was found between $R V / L V \geq 1$ and mortality $(p=0.908)$. All patients with PTE-related mortality had $R V / L V$ ratio $\geq 1$ in CTPA and had IVC reflux. Patients with an RV/LV ratio of $\geq 1$ had statistically significantly higher troponin levels $(p=0.004)$ and IVC reflux $(p=0.025)$ compared to patients with an RV/LV ratio of $<1$.

Conclusion: In conclusion, RV/LV ratio should be evaluated together with cardiac biomarkers to define mortality risk.

Key words: Mortality; pulmonary embolism; risk classification; right ventricle; ventricular dysfunction 
ÖZ

\section{RV/LV oranı ve kardiyak biyobelirteçlerin pulmoner emboliye bağlı mortalite riskini tanımlamada kullanımı}

Giriş: Akut pulmoner tromboembolizm (PTE), kardiyovasküler mortalitenin yaygın bir nedenidir. Sağ ventriküler (RV) disfonksiyon en önemli ölüm nedenidir. Bilgisayarlı Tomografi Pulmoner Anjiyografi (BTPA), tanı anında RV işlev bozukluğunun bir göstergesi olan sağ ventrikül genişlemesini tespit edebilir. Bu çalışma, BTPA'da RV işlev bozukluğunu gösteren parametreleri ve erken ölüm bulgularının korelasyonunu belirlemeyi amaçlamaktadır.

Materyal ve Metod: Bu retrospektif çalışmada Ocak 2012-Aralık 2017 tarihleri arasında CTPA ile PTE tanısı alan hastaların elektronik dosyaları değerlendirildi. Kalp odaları, IVC reflü ve IVS morfolojisi ölçümleri hesaplandı. Akut PTE tanısı sonrası hastaların hastane içi mortalitesi değerlendirildi.

Bulgular: 206 uygun hasta vardı. Değerlendirilen radyolojik parametreler arasında sağ atriyum (RA) boyutu $(p=0,002), P A$ boyutu $(p=0,003)$, Ao boyutu $(p=0,006)$ ve IVC reflü varlığı $(p=0,001)$ mortalite ile ilişkilendirildi. $R V / L V \geq 1$ ile mortalite arasında anlamlı bir ilişki bulunmadı $(p=0,908)$. PTE ile ilişkili mortaliteye sahip tüm hastalarda BTPA'da RV/LV oranı $\geq 1$ ve IVC reflü vardı. RV/LV oranı 1 olan hastalar, RV/LV oranı <1 olan hastalara kıyasla istatistiksel olarak anlamlı şekilde daha yüksek troponin düzeylerine $(p=0,004)$ ve IVC reflüsüne $(p=0,025)$ sahipti.

Sonuç: Ölüm riskini tanımlamak için RV/LV oranı kardiyak biyobelirteçlerle birlikte değerlendirilmelidir.

Anahtar kelimeler: Mortalite; pulmoner emboli; risk sınıflandırması; să̆ ventrikül; ventriküler disfonksiyon

\section{INTRODUCTION}

Acute pulmonary thromboembolism (PTE) is a common cause of cardiovascular mortality (1). Especially right ventricular (RV) dysfunction or injury is the most important cause of increased mortality $(2,3)$. Current guidelines recommend the classification of patients with PTE according to the risk of early mortality in clinical follow-up and treatment management. Clinical risk assessment scores, biomarkers, and imaging methods are used in risk classification. However, in normotensive PTE patients; none of the findings such as high risk in clinical scoring, presence of RV dysfunction, or high cardiac markers alone is sufficient to determine the risk of early poor prognosis (4-6). A meta-analysis showed that the presence of RV dysfunction on admission was associated with an increased risk of premature death in patients classified as low-risk, based solely on clinical scoring (7). So that the 2014 European Society of Cardiology (ESC) Pulmonary Embolism Guideline states that RV dysfunction assessment is not necessary for low-risk patients, however, in 2019 update, assessment of RV dysfunction with imaging or laboratory biomarkers, even in the presence of low clinical scoring is recommended $(6,8)$.

RV dysfunction in PE patients can be evaluated by echocardiography (echo) or Computed Tomography Pulmonary Angiography (CTPA). However, CTPA, which is widely used in the diagnosis of PTE, can detect RV enlargement which is an indicator of RV dysfunction at the time of diagnosis. Studies have shown that an increased RV/LV (left ventricular) ratio is an independent predictor of PTE-related mortality and is also used in risk classification $(2,3,6,9)$. Also, thrombus burden and distribution can be evaluated with pulmonary artery (PA) diameter, aortic (Ao) diameter, interventricular septum (IVS) morphology, and inferior vena cava (IVC) reflux.

Risk stratification for PTE patients is important to ensure appropriate treatment, patient management and determine prognosis. Thus, patients with high mortality risk associated with PTE; it can be detected while still in the emergency room and evaluated in terms of thrombolytic therapy, intensive care follow-up, long-term hospital stay or close follow-up. also, low-risk patients can be discharged earlier and treated with anticoagulants. This study aims to determine the parameters indicating RV dysfunction in CTPA and correlation of CT findings with early mortality by using CTPA findings, clinical and laboratory findings in patients diagnosed with PTE.

\section{MATERIALS and METHODS}

In this retrospective study, electronic files of patients diagnosed with PTE with CTPA between January 2012 and December 2017 in the emergency department or outpatient clinic were evaluated. This study was approved by the Ethics Committee of our institutional board (Decision No: 08-431-17, Date: 24.04.2017).

Patients diagnosed with thorax CT and those with CTPA attraction phase incompatibility and movement artifact were excluded because measurements of heart chambers, IVC reflux, and IVS morphology could not be evaluated (Figure 1). The in-hospital mortality of patients after acute PTE diagnosis was evaluated. 


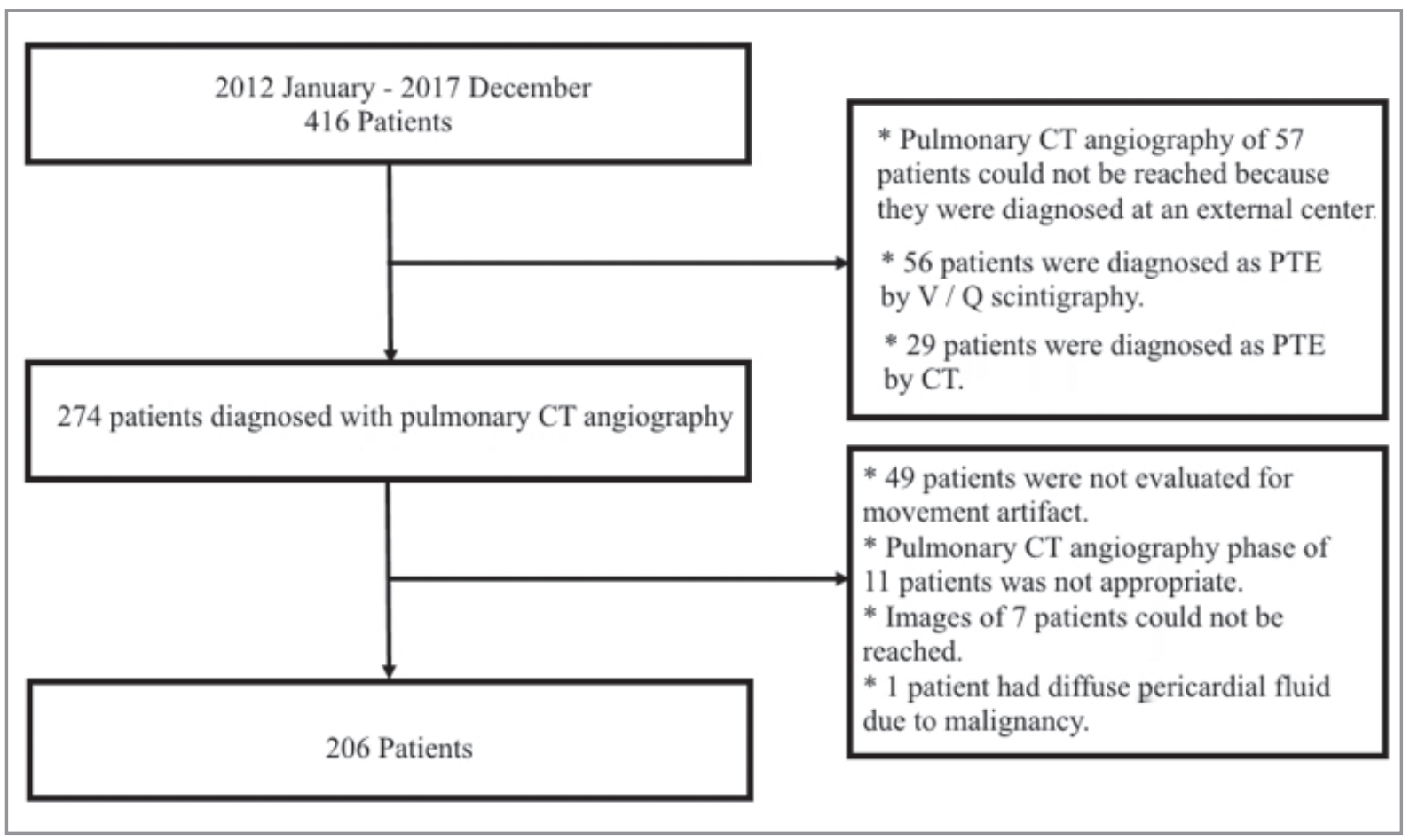

Figure 1. Study population criteria.

\section{Clinical Data}

Patients' age, sex, arterial blood gas, Troponin, D-dimer, brain natriuretic peptide (BNP) values, the duration of hospital stay, the presence of in-hospital mortality, treatment, and comorbidities such as cancer, heart failure, chronic lung disease, and diabetes, hypertension, cerebrovascular diseases, were recorded. Troponin value> $0.05 \mathrm{ng} / \mathrm{ml}$ was considered as high troponin, BNP> $150 \mathrm{pg} / \mathrm{ml}$ was considered as high BNP. Patients were grouped into low, moderate, and high-risk groups according to the "2019 ESC Guidelines on the Diagnosis and Management of Acute Pulmonary Embolism" risk classification (6).

\section{Computed Tomography (CT) Imaging Analysis}

All examinations were performed on 64-detector row (Toshiba Aquilion, Otawara, Japan) and 16-detector row (General Electrics Healthcare Bright Speed Delight, Milwaukee, USA; Siemens Somatom Sensation, Forchheim, Germany) CT scanners. CTPA evaluation of patients was performed by two radiologists, each with more than four years of experience. $\mathrm{RV}$ and LV measurements were done by evaluating the ventricle diameters in the standard axial view, measuring the maximal distance between the ventricular endocardium and the interventricular septum, perpen- dicular to the long axis of the heart, and using the maximum dimensions for both ventricles which may be found at different levels. Measuring RV/LV ratio $\geq 1$ was considered as RV dysfunction (Figure 2A and 2B). The right atrium and left atrium dimensions were calculated by measuring the widest distance between the interatrial septum and lateral atrial wall at the aortic root level (Figure 3). PA and ascending Ao diameter were calculated on the axial image at the level where the main pulmonary trunk was consistent with the right pulmonary artery. PA/Ao ratio was calculated. IVS morphology was defined as normal (convex to the right ventricle), flattened, or bent (convex to the left ventricle). When contrast material was detected in the intrahepatic part of the IVC, contrast media reflux was recorded (Figure $4 \mathrm{~A}$ and $4 \mathrm{~B}$ ). If a peripheral wedgeshaped consolidation showing internal lucencies was present, pulmonary infarct was noted.

\section{Statistical Analysis}

Data analysis was performed using SPSS for Windows 18 package program. Descriptive statistics are shown as mean \pm standard deviation for variables with normal distribution, median (min-max) for variables with abnormal distribution, number of cases, and (\%) for nominal variables. 


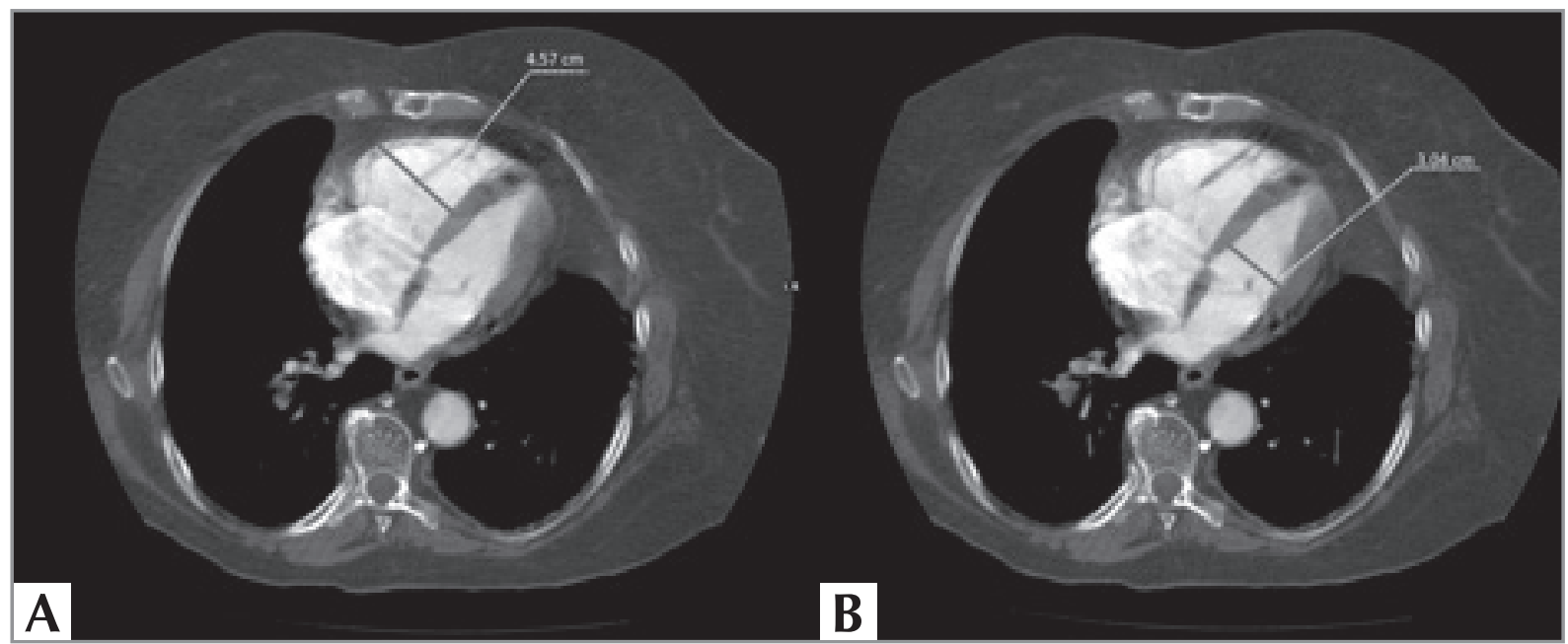

Figure 2. A. Right ventricular (RV) and B. left ventricular (LV) measurements were measured from axial CT images by determining maximal length between ventricular endocardium and interventricular septum.

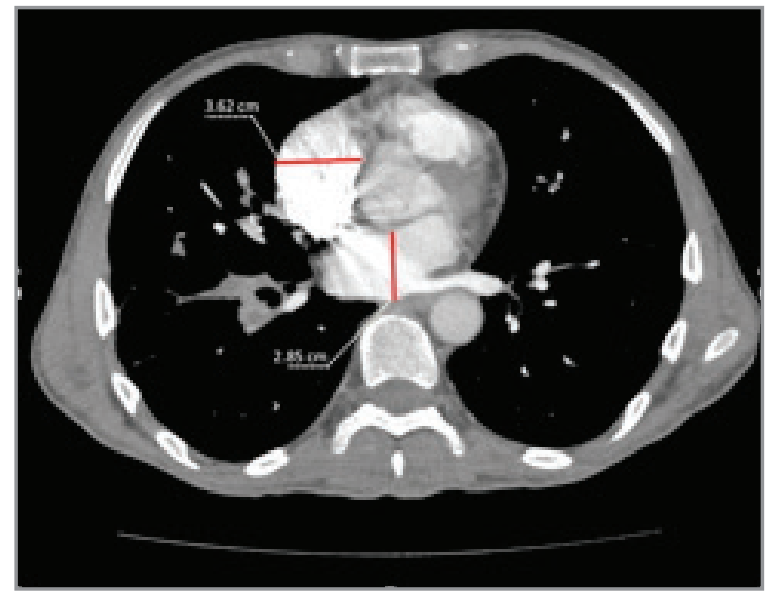

Figure 3. Right atrium and left atrium dimensions were calculated by measuring the widest distance between the interatrial septum and lateral atrial wall at the aortic root level.
The significance of the difference between the groups in terms of means was investigated by "t-Test" and the significance of the difference in terms of median values was investigated by the "Mann-Whitney $U$ Test". Nominal variables were evaluated by the "Pearson Chi-Square Test" or "Fisher Exact Test".

While the relationship between continuous variables was investigated, the "Pearson Correlation Test" was used for normal distribution, and the "Spearman Correlation Test" was used to assess the absence of normal distribution. " $p$ " values less than 0.05 were considered statistically significant.

\section{RESULTS}

There were 206 eligible patients. A summary of their characteristics is shown in Table 1. All-cause mortality

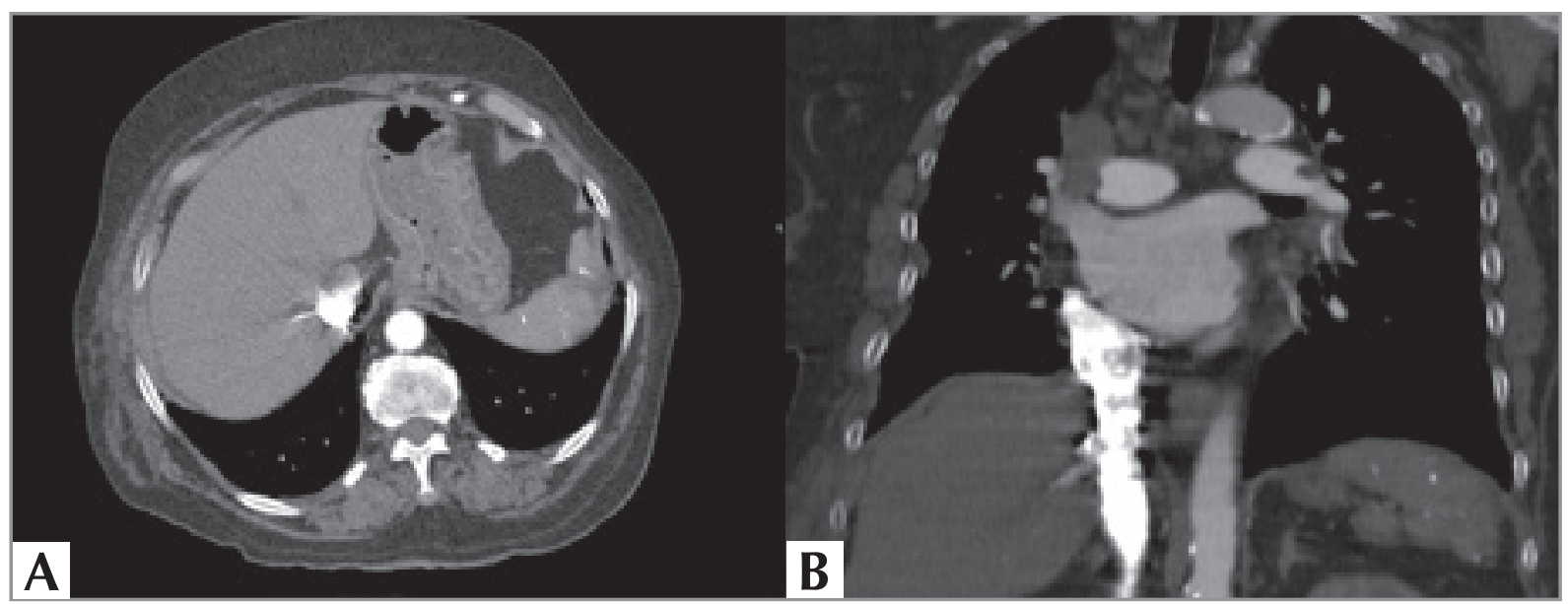

Figure 4. A. Axial and B. coronal CT images show that contrast material was detected in the intrahepatic part of the inferior vena cava (IVC). 
Table 1. Baseline characteristics of the study population

$n=206(\%)$

Sex

Female

Male

Age (mean $\pm \mathrm{SD})$

Cancer history

Heart failure

Choric lung diseases

Other additional diseases*

$\mathrm{CCl}^{\dagger}$ (median, min-max)

Elevated troponin I ( $>0.05 \mathrm{pg} / \mathrm{ml})$

Elevated BNP ${ }^{\ddagger}(>150 \mathrm{pg} / \mathrm{ml})$

Echo-RVD ${ }^{\S}$ (144 patients)

$\mathrm{RV}^{\mathrm{Il} / \mathrm{LV}}{ }^{\Uparrow}$ Ratio $\geq 1$

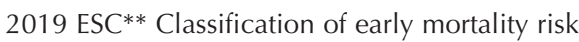

Low Risk

Intermediate-low risk

Intermediate-high risk

High risk

All cause mortality

PE-related mortality

Other causes mortality
$108(52.4)$

98 (47.6)

$63.3 \pm 16.27$

$58(28.2)$

$15(7.3)$

27 (13.7)

$123(57.7)$

2 (0-13)

58 (34.9)

27 (47.4)

$121(69.4)$

121 (58.7)

$30(14.9)$

118 (58.7)

44 (21.9)

$9(4.5)$

26 (12.6)

$5(19.2)$

21 (80.8)

*Other additional diseases: Diabetes mellitus, Hypertension, Cerebrovascular diseases, etc.

**ESC: European Society of Cardiology.

${ }^{\dagger} \mathrm{CCl}$ : Charlson comorbidity index, ${ }^{\ddagger} \mathrm{BNP}$ : Brain natriuretic peptid, ${ }_{\mathrm{S}} \mathrm{RVD}$ : Right ventricle dysfunction, $\|_{\mathrm{RV}}$ : Right ventricle, ${ }^{\circledR} \mathrm{LV}$ : Left ventricle.

was $12.6 \%$ (26/206). Five patients (19.2\%) died due to PTE or complications. One of the patients who died due to PTE was an intermediate-low risk, three were intermediate-high risk and one was high-risk. Catheterdirected thrombolysis (CDT) was performed in one of the patients who died due to PTE and died due to the procedure complication. Four of them died due to right heart failure and hemodynamic collapse.

Compared to survivors, age, comorbidities, D-dimer, and troponin levels were statistically significantly higher in the mortality group. There wasn't any correlation between BNP levels and mortality. Mortality rates in patients with and without echocardiographic signs of RV dysfunction were $12.4 \%$ and $4.3 \%$ respectively $(p=0.260)$. However, median systolic pulmonary artery pressure (sPAP) was significantly higher in the mortality group $(52.5 \mathrm{mmHg}$ vs. 45 $\mathrm{mmHg})(p=0.001)$. Also, mortality was significantly higher in patients with right ventricular dilatation using echo $(p=0.027)$. There was a significant cor- relation between ESC risk classification and all-cause mortality $(p=0.001)$.

In CTPA measurements, RV/LV $\geq 1$ was in 121 patients $(58.7 \%)$ and $\mathrm{PA} / \mathrm{Ao}$ was $\geq 1$ in 51 patients $(26.8 \%)$. The IVS was bent to the left in 26 patients $(12.6 \%)$ and flattened in 92 patients (44.7\%). Rate of pulmonary infarction and IVC reflux were $42.7 \%(n=88)$ and $59.7 \%(n=123)$ respectively. CTPA signs of patients with and without all-caused mortality are shown in Table 2. No significant relationship was found between $R V / L V \geq 1$ and mortality $(p=0.908)$. All patients with PTE-related mortality had RV/LV ratio $\geq 1$ in CTPA and had IVC reflux (Table 2 ).

Patients with an RV/LV ratio of $\geq 1$ had statistically significantly higher troponin levels $(p=0.004)$ and IVC reflux ( $p=0.025)$ compared to patients with an RV/LV ratio of $<1$ (Table 3 ).

There was a moderate but significant positive correlation between RA size and sPAP $(r=0.465)(p<0.001)$ 
Prognostic utility of computed tomography pulmonary angiography findings

Table 2. CTPA* signs of patients with and without all-caused mortality

\section{All-Caused Mortality}

\begin{tabular}{|c|c|c|c|}
\hline & Number of Survivors & Number of Deceased Patients & $\mathbf{p}$ \\
\hline $\mathrm{RA}^{\dagger}$ Diamater, mm (median, min-max) & $33.5(25-41)$ & $32(20-41)$ & 0.002 \\
\hline $\mathrm{LA}^{\ddagger}$ Diamater, mm (median, min-max) & $38(23-44)$ & $30(17-58)$ & 0.125 \\
\hline $\mathrm{RV}^{\S}$ Diamater, mm (median, min-max) & $41(28-47)$ & $46(25-58)$ & 0.083 \\
\hline LVIl Diamater, mm (median, min-max) & $42(30-47)$ & $34(21-50)$ & 0.187 \\
\hline PA Diamater, mm (median, min-max) & $30.5(22-42)$ & $27(19-55)$ & 0.003 \\
\hline $\mathrm{Ao}^{* *}$ Diamater, mm (median, min-max) & $35(26-44)$ & $33(20-52)$ & 0.006 \\
\hline \multicolumn{4}{|l|}{ RV/LV ratio $(\mathrm{n}, \%)$} \\
\hline$\geq 1$ & $15(12.4)$ & $106(87.6)$ & \multirow{2}{*}{0.908} \\
\hline$<1$ & $11(12.9)$ & $74(87.1)$ & \\
\hline \multicolumn{4}{|l|}{$\mathrm{PA} /$ Ao ratio $(\mathrm{n}, \%)$} \\
\hline$\geq 1$ & $9(17.6)$ & $42(82.4)$ & \multirow{2}{*}{0.213} \\
\hline$<1$ & $17(11)$ & $138(89)$ & \\
\hline \multicolumn{4}{|l|}{ Contrast medium reflux into $\mathrm{IVC}^{\dagger+}(\mathrm{n}, \%)$} \\
\hline Present & $23(18.7)$ & $100(81.3)$ & \multirow{2}{*}{0.001} \\
\hline None & $3(3.6)$ & $80(96.4)$ & \\
\hline
\end{tabular}

Table 3. CTPA* Signs of Patients with RV/LV+ Ratio $\geq 1$ vs. $<1$

\begin{tabular}{|c|c|c|c|}
\hline & \multicolumn{2}{|c|}{ RV/LV } & \multirow[b]{2}{*}{$\mathbf{p}$} \\
\hline & $\begin{array}{c}\text { Right to left ventricular } \\
\text { ratio }<1 \text { on MDCT }(n, \%)\end{array}$ & $\begin{array}{c}\text { Right to left ventricular } \\
\text { ratio } \geq 1 \text { on } \operatorname{MDCT}(n, \%)\end{array}$ & \\
\hline Troponin ng/ml (median, min-max) & $0.20(0.01-0.30)$ & $0.950(0.01-2.16)$ & 0.004 \\
\hline $\mathrm{BNP}^{\ddagger} \mathrm{pg} / \mathrm{mL}$ (median, min-max) & $110(6.9-780)$ & $354(10-10000)$ & 0.056 \\
\hline $\mathrm{RA}^{\S}$ Diamater mm (median, min-max) & $27(20-41)$ & $33(23-41)$ & 0.058 \\
\hline LA"l Diamater mm (median, min-max) & $28(20-58)$ & $32(17-46)$ & 0,011 \\
\hline PA Diamater mm (median, min-max) & $24(21-26)$ & $29.5(22-35)$ & $<0.001$ \\
\hline Ao** Diamater mm (median, min-max) $^{*}$ & $31(27-42)$ & $34(20-39)$ & 0.068 \\
\hline \multicolumn{4}{|l|}{ PA/Ao } \\
\hline$\geq 1$ & $11(21.6)$ & $40(78.4)$ & 0.001 \\
\hline$<1$ & $73(47.7)$ & $81(52.3)$ & \\
\hline \multicolumn{4}{|l|}{$\mathrm{IVC}^{+\dagger}$ Reflux } \\
\hline Present & $43(35)$ & $80(65)$ & 0.025 \\
\hline None & $42(50.6)$ & $41(49.4)$ & \\
\hline \multicolumn{4}{|l|}{ Pulmonary infarction } \\
\hline Present & $41(48.2)$ & $47(38.8)$ & 0.180 \\
\hline None & $44(51.8)$ & $74(61.2)$ & \\
\hline
\end{tabular}

(Figure 5). There was also a moderate but significant correlation between sPAP and pulmonary artery size $(r=0.465)(p<0.001)$ (Figure 6). ROC curve analysis was performed to find an appropriate sPAP value in predicting disease severity and mortality in PTE patients. However, the confidence interval of the area under the curve was seen to be less than 0.5. 


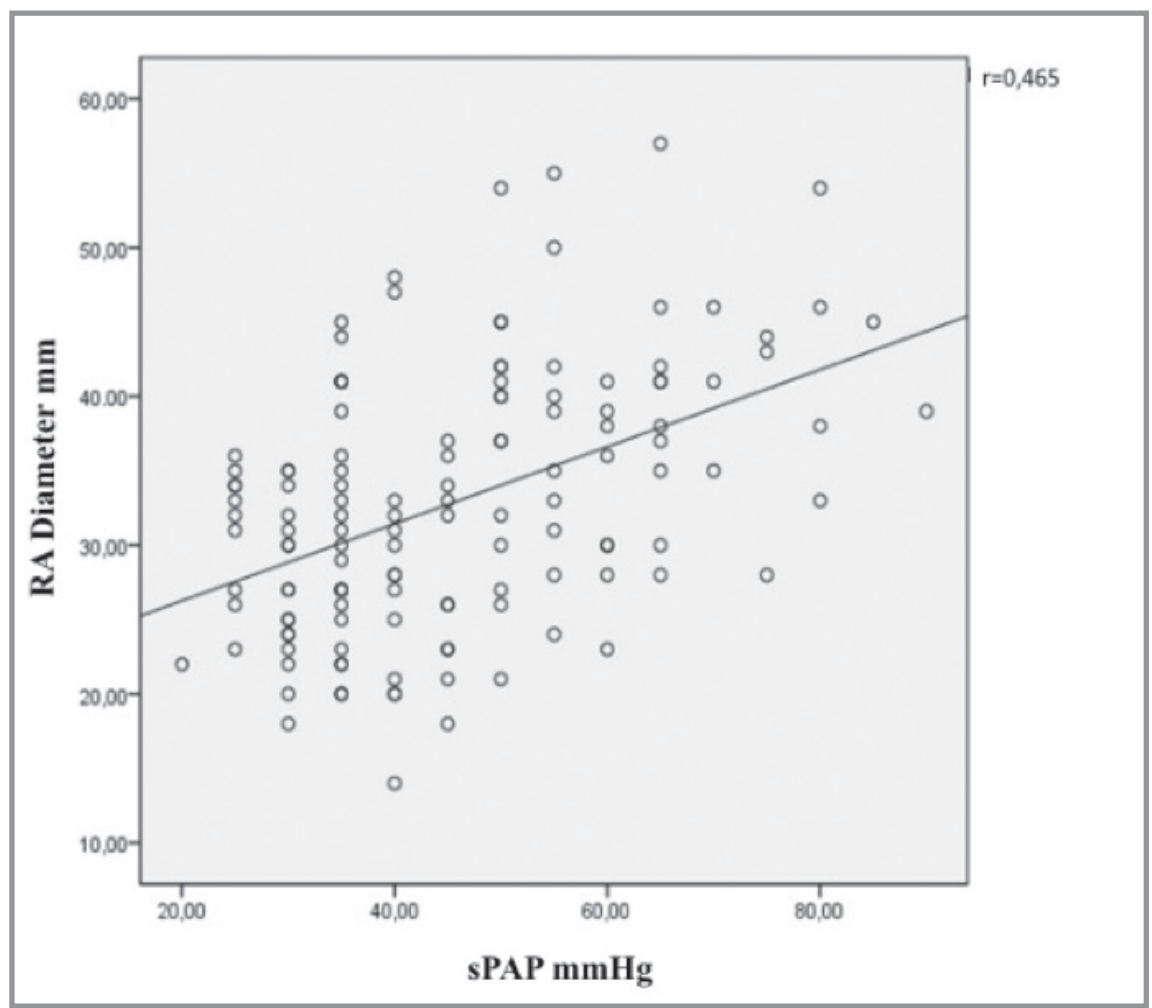

Figure 5. Correlation between SPAP (systolic pulmonary artery pressure) and RA (right atrium) diameter.

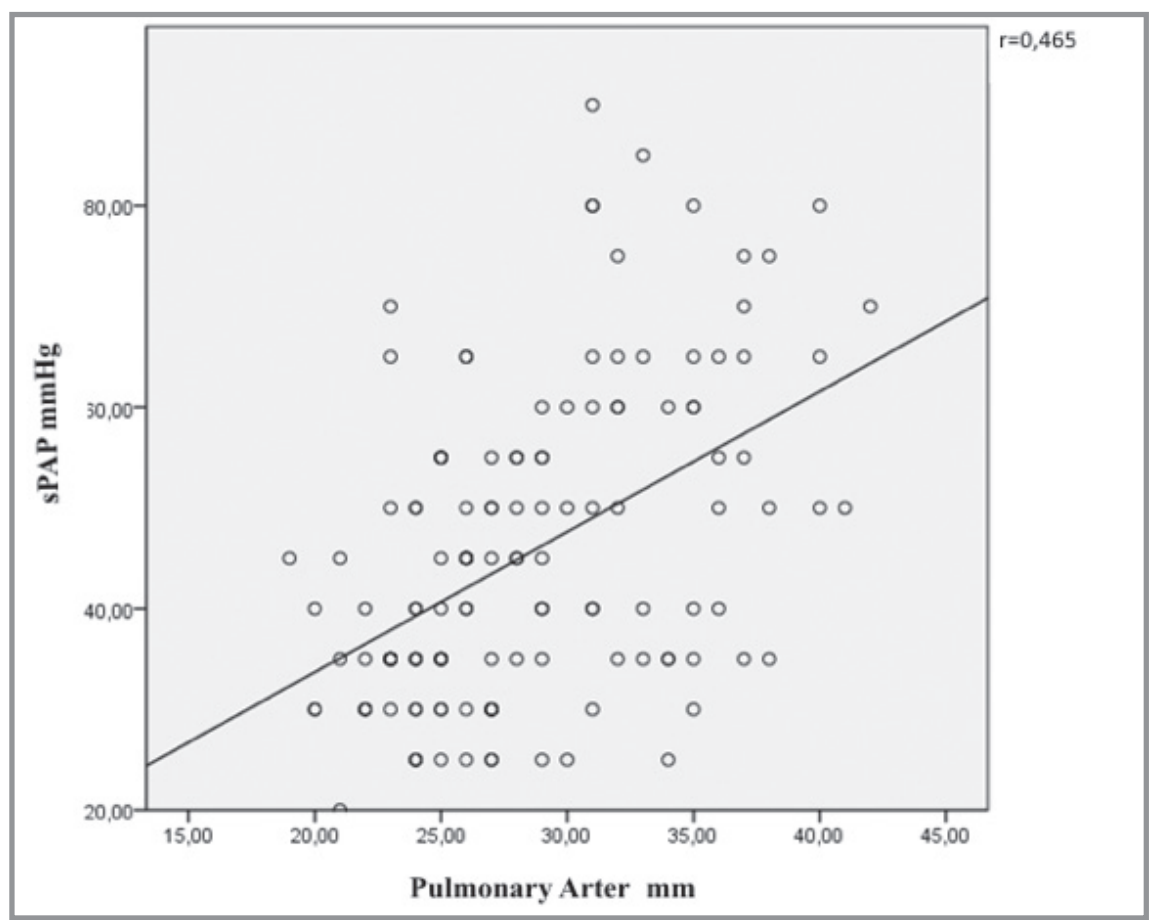

Figure 6. Correlation between SPAP (systolic pulmonary artery pressure) and pulmonary arter diameter. 


\section{DISCUSSION}

Though CTPA is widely used in the diagnosis of PTE, its prognostic significance is controversial. Some studies have shown a significant relationship between increased RV/LV ratio and all-cause mortality and PTErelated mortality $(4,9-14)$. On the other hand, there are studies without any apparent correlation between RV/ LV ratio and mortality. In PROTECT study, the prognostic significance of CTPA findings was evaluated in patients with hemodynamically stable 848 PTE patients and there wasn't any association between RV dysfunction evaluated by CTPA and 30-day all-cause death (15). In another study, in 779 PTE patients with simplified pulmonary embolism severity index (SPESI) 0 , the RV/LV ratio was not associated with an increase in allcause mortality (16). In a recent a meta-analysis showed that CTPA findings including RV dilatation did not predict short-term mortality and other adverse clinical outcomes in hemodynamically stable patients (17).

In our study, though RV/LV was $\geq 1$ in all deceased patients, there wasn't a statistically significant relation between RV/LV ratio and mortality. As the peitho study showed most of the patients with intermediate highrisk $\mathrm{PE}$, discharge without any morbidity or mortality (18). Right ventricular dilatation is a sign of cardiac stress due to PE, but not a sign of increased mortality. Because compensation is very effective in most of the patients $(8,19,20)$. Also, RV/LV ratio might be affected by advanced age, chronic lung diseases, or cardiovascular diseases. Especially in patients with advanced age, the rate of cardiopulmonary comorbidities are high. Also acute on chronic PE is a possibility and discrimination between acute and chronic PE is not always easy despite some specific CT findings chronic PE $(21,22)$. In our study, comorbidities were much higher in patients with all-cause mortality, and these patients were older. As it is known, mortality increases in the presence of advanced age and comorbidity in acute PTE patients (23-26).

The presence of IVC contrast reflux is another CTPA finding which has been searched for prognostic significance in acute PTE. Studies have shown a correlation between IVC contrast reflux and thrombus burden (12) and mortality (12,27-29). Heyer et al. found a relationship between IVC contrast reflux and the need for intensive care in PTE patients (14). In our study, IVC reflux was present in $59.7 \%$ of patients, and in line with previous studies, IVC contrast reflux was statistically significantly associated with PE related and allcause mortality. IVC contrast reflux is a result of tricus- pid valve regurgitation, right ventricular dilatation and decreased right ventricular output (14).

Regarding the uncertainty in RV/LV cut-off ratio, variability in radiological measurement method and study results, it is clear that RV/LV ratio alone is not sufficient to show prognosis. Recent data show that increased plasma cardiac troponin, an indicator of myocardial ischemia is associated with an increase in all-cause mortality in patients with PTE. It has been shown that $40-70 \%$ of PTE patients with high troponins have RV dysfunction (30). Accordingly, the RV/LV ratio should be evaluated together with cardiac biomarkers to determine the risk of PTE-related mortality. In our study, troponin levels were higher in deceased patients and patients with RV/LV $\geq 1$. However, we did not find any correlation between BNP value and RV dilatation and all-cause mortality. D-dimer levels were also higher in patients who deceased. Studies have found a relationship between Troponin, D-dimer levels, and RV dysfunction and mortality. According to these studies, increased D-dimer and Troponin levels would help to identify hemodynamically stable submassive PTE patients (31-34). In a large meta-analysis of 10842 patients including 46 studies by El-Manyar et al., high serum troponin was found to be associated with higher mortality in PE patients regardless of the troponin test used. In a meta-analysis, higher troponin levels were associated with a higher risk of death than normal troponin levels (35). A meta-analysis by Barco et al. showed that RV dysfunction and high troponin and BNP have prognostic value in Echo and CTPA (36).

In our study, pulmonary artery and aortic diameter were statistically significantly increased in patients who died due to PE compared to those who survived. The expansion of PA in CTPA is indicative of increased pulmonary pressure (37). Liu et al. found a correlation between PA size and sPAP. In the same study, there was a correlation between SPAP and rate of occluded areas, RV/LV ratio, PA/Ao ratio (38). In our study, a similar result was obtained. There was a correlation between SPAP and PA size. This can be explained by the presence of comorbidities such as advanced age, hypertension and congestive heart failure that affect the Ao dimension in the study population.

In this study, RA size was increased in patients with higher SPAP and all-cause mortality, and a correlation was found between RA and sPAP. RA volume increases by as a compensatory response to $R V$ pressure increase. In previous studies, increased RA size was associated with the severity of pulmonary artery obstruction 
$(39,40)$. In a study, RA/RV ratio was found to be an indicator of 30-day mortality in normotensive PE patients (41). RA dilatation, a consequence of pulmonary hypertension, is an indicator of adverse clinical outcomes in patients with pulmonary arterial hypertension (PAH) (42). Accordingly, RA size has a prognostic significance in PTE patients as well as in PAH patients.

Limitations of this study include the small sample size, retrospective design and the study was performed in a single center.

\section{CONCLUSION}

In conclusion, presence of IVC reflux, increased PA diameter and RA size, which are among the CT findings of RV dysfunction, are associated with mortality. However, the increased RV/LV ratio was not associated with mortality. RV/LV ratio should be evaluated together with cardiac biomarkers to define mortality risk.

Ethical Committee Approval: The approval for this study was obtained from Ankara University Faculty of Medicine Clinical Research Ethical Committee (Decision No: 08-431-17, Date: 24.04.2017).

\section{CONFLICT of INTEREST}

The authors declare no conflicts of interest.

\section{AUTHORSHIP CONTRIBUTIONS}

\section{Concept/Design: SA, is}

Analysis/Interpretation: SA, SE, ÖA, AGK

Data acqusition: SA, SE, MK, AGÇ, AGK

Writing: SA, SE, MK, AGK

Clinical Revision: SE, ÖA, AK

Final Approval: SA, ÖA, AK, is

\section{REFERENCES}

1. Barco S, Schmidtmann I, Ageno W, Bauersachs RM, Becattini C, Bernardi E, et al. Early discharge and home treatment of patients with low-risk pulmonary embolism with the oral factor Xa inhibitor rivaroxaban: an international multicentre single-arm clinical trial. Eur Heart J 2020; 41(4): 509-18.

2. Bikdeli B, Lobo IL, Jimenez D, Philip Green P, FernándezCapitán C, Bura-Riviere A, et al. Early use of echocardiography in patients with acute pulmonary embolism: findings from the RIETE registry. I Am Heart Assoc 2018; 7(17): e009042.

3. Meinel FG, Nance JW Jr., Schoepf UJ, Hoffmann VS, Thierfelder KM, Costello P, et al. Predictive value of computed tomography in acute pulmonary embolism: systematic review and meta-analysis. Am J Med 2015; 128(7): 747-59.e2.
4. Devaraj A, Sayer C, Sheard S, Grubnic S, Nair A, Vlahos I. Diagnosing acute pulmonary embolism with computed tomography: imaging update. I Thorac Imaging 2015; 30(3): 176-92.

5. Turkish Thoracic Society, Pulmonary Thromboembolism Diagnosis And Treatment Comparison Report, 2015.

6. Konstantinides SV, Meyer G, Becattini C, Bueno $H$ Geersing GJ, Harjola VP, et al. 2019 ESC Guidelines for the diagnosis and management of acute pulmonary embolism developed in collaboration with the European Respiratory Society (ERS). Eur Respir J 2019; 54(3): 1901647.

7. Barco S, Mahmoudpour SH, Planquette B, Sanchez $O$, Konstantinides SV, Meyer G. Prognostic value of right ventricular dysfunction or elevated cardiac biomarkers in patients with low-risk pulmonary embolism: a systematic review and meta-analysis. Barco S, Mahmoudpour SH, Planquette B, Sanchez O, Konstantinides SV, Meyer G. Prognostic value of right ventricular dysfunction or elevated cardiac biomarkers in patients with low-risk pulmonary embolism: a systematic review and meta-analysis. Eur Heart J 2019; 40(11): 902-10.

8. Konstantinides SV. 2014 ESC Guidelines on the diagnosis and management of acute pulmonary embolism. Eur Heart J 2014; 35(45): 3145-6.

9. George E, Kumamaru KK, Ghosh N, Gonzalez Quesada C, Wake N, Bedayat A, et al. Computed tomography and echocardiography in patients with acute pulmonary embolism: part 2: prognostic value. I Thorac Imaging 2014; 29(1): W7-12.

10. Becattini C, Agnelli G, Germini F, Vedovati MC. Computed tomography to assess risk of death in acute pulmonary embolism: a meta-analysis. Eur Respir J 2014; 43(6): 1678-90.

11. Baptista R, Santiago I, Jorge E, Teixeira R, Mendes P, CurvoSemedo L, et al. One-shot diagnostic and prognostic assessment in intermediate- to high-risk acute pulmonary embolism: the role of multidetector computed tomography. Rev Port Cardiol 2013; 32(1): 7-13.

12. Furlan A, Aghayev A, Chang CC, Patil A, Jeon KN, Park B, et al. Short-term mortality in acute pulmonary embolism: clot burden and signs of right heart dysfunction at CT pulmonary angiography. Radiolo 2012; 265(1): 283-93.

13. Ende-Verhaar YM, Kroft LJM, Mos ICM, Huisman MV, Klok FA. Accuracy and reproducibility of CT right-to-left ventricular diameter measurement in patients with acute pulmonary embolism. PloS One 2017; 12(11): e0188862.

14. Heyer CM, Lemburg SP, Knoop H, Holland-Letz T, Nicolas $V$, Roggenland D. Multidetector-CT angiography in pulmonary embolism-can image parameters predict clinical outcome? Eur Radiol 2011; 21(9): 1928-37.

15. Jimenez $D$, Lobo $L$, Monreal $M$, Moores $L$, Oribe $M$, Barron $M$, et al. Prognostic significance of multidetector CT in normotensive patients with pulmonary embolism: results of the protect study. Thorax 2014; 69(2): 109-15.

16. Cote B, Jimenez D, Planquette B, Roche A, Marey J, Pastre $J$, et al. Prognostic value of right ventricular dilatation in patients with low-risk pulmonary embolism. Eur Respir J 2017; 50(6): 1701611. 
17. Coutance G, Cauderlier E, Ehtisham J, Hamon M, Hamon $M$. The prognostic value of markers of right ventricular dysfunction in pulmonary embolism: a meta-analysis. Crit Care $2011 ; 15(2):$ R103.

18. Meyer G, Vicaut E, Danays T, Agnelli G, Becattini C, BeyerWestendorf J, et al. Fibrinolysis for patients with intermediate-risk pulmonary embolism. N Engl J Med 2014; 370(15): 1402-11.

19. Huisman MV, Barco S, Cannegieter SC, Le Gal G, Konstantinides SV, Reitsma PH, et al. Pulmonary embolism. Nat Rev Dis Primers 2018; 4: 18028.

20. Wood KE. Major pulmonary embolism: review of a pathophysiologic approach to the golden hour of hemodynamically significant pulmonary embolism. Chest 2002; 121(3): 877-905.

21. Rali PM, Criner GJ. Submassive pulmonary embolism. Am J Respir Crit Care Med 2018; 198(5): 588-98.

22. Klok FA, Delcroix M, Bogaard HJ. Chronic thromboembolic pulmonary hypertension from the perspective of patients with pulmonary embolism. I Thromb Haemost 2018; 16(6): 1040-51.

23. Masotti L, Ray P, Righini M, Le Gal G, Antonelli F, Landini $G$, et al. Pulmonary embolism in the elderly: a review on clinical, instrumental and laboratory presentation. Vasc Health Risk Manag 2008; 4(3): 629-36.

24. Ng AC, Chow V, Yong AS, Chung $T$, Kritharides $L$. Prognostic impact of the Charlson comorbidity index on mortality following acute pulmonary embolism. Respiration 2013; 85(5): 408-16.

25. Kohn CG, Mearns ES, Parker MW, Hernandez AV, Coleman Cl. Prognostic accuracy of clinical prediction rules for early post-pulmonary embolism all-cause mortality: a bivariate meta-analysis. Chest 2015; 147(4): 1043-62.

26. de Miguel-Diez J, Jimenez-Garcia R, Jimenez D, Monreal $M$, Guijarro R, Otero R, et al. Trends in hospital admissions for pulmonary embolism in Spain from 2002 to 2011. Eur Respir J 2014; 44(4): 942-50.

27. Ghaye B, Ghuysen A, Willems $V$, Lambermont B, Gerard $P$, $D^{\prime}$ Orio $V$, et al. Severe pulmonary embolism:pulmonary artery clot load scores and cardiovascular parameters as predictors of mortality. Radiol 2006; 239(3): 884-91.

28. Kumamaru KK, George E, Aghayev A, Saboo SS, Khandelwal A, Rodriguez-Lopez S, et al. Implementation and performance of automated software for computing right-to-left ventricular diameter ratio from computed tomography pulmonary angiography images. I Comput Assist Tomogr 2016; 40(3): 387-92.

29. Bach AG, Nansalmaa B, Kranz J, Taute BM, Wienke $A$, Schramm D, et al. CT pulmonary angiography findings that predict 30-day mortality in patients with acute pulmonary embolism. Eur J Radiol 2015; 84(2): 332-7.

30. El-Menyar A, Sathian B, Al-Thani H. Elevated serum cardiac troponin and mortality in acute pulmonary embolism: Systematic review and meta-analysis. Respir Med 2019; 157: $26-35$
31. Becattini C, Lignani A, Masotti L, Forte MB, Agnelli G. $D$-dimer for risk stratification in patients with acute pulmonary embolism. J Thromb Thrombolysis 2012; 33(1): 48-57.

32. Keller K, Beule J, Schulz A, Coldewey M, Dippold W, Balzer JO. D-dimer for risk stratification in haemodynamically stable patients with acute pulmonary embolism. Adv Med Sci 2015; 60(2): 204-10.

33. Maestre A, Trujillo-Santos J, Visona A, Lobo JL, Grau E, Maly $R$, et al. D-dimer levels and 90-day outcome in patients with acute pulmonary embolism with or without cancer. Thromb Res 2014; 133(3): 384-9.

34. Lee Chuy K, Hakemi EU, Alyousef T, Dang G, Doukky R. The long-term prognostic value of highly sensitive cardiac troponin I in patients with acute pulmonary embolism. Clinical Cardiol 2017; 40(12): 1271-8.

35. Bajaj A, Saleeb M, Rathor P, Sehgal V, Kabak B, Hosur S. Prognostic value of troponins in acute nonmassive pulmonary embolism: a meta-analysis. Heart Lung 2015; 44(4): 327-34.

36. Barco S, Mahmoudpour SH, Planquette B, Sanchez O, Konstantinides SV, Meyer G. Prognostic value of right ventricular dysfunction or elevated cardiac biomarkers in patients with low-risk pulmonary embolism: a systematic review and meta-analysis. Eur Heart J 2019; 40(11): 90210.

37. Staskiewicz G, Czekajska-Chehab E, Uhlig S, Przegalinski J, Maciejewski R, Drop A. Logistic regression model for identification of right ventricular dysfunction in patients with acute pulmonary embolism by means of computed tomography. Eur J Radiol 2013; 82(8): 1236-9.

38. Liu YY, Li XC, Duan Z, Yuan YD. Correlation between the embolism area and pulmonary arterial systolic pressure as an indicator of pulmonary arterial hypertension in patients with acute pulmonary thromboembolism. Eur Rev Med Pharmacol Sci 2014; 18(17): 2551-5.

39. Chow V, Ng AC, Chung T, Thomas L, Kritharides L. Right atrial to left atrial area ratio on early echocardiography predicts long-term survival after acute pulmonary embolism. Cardiovasc Ultrasound 2013; 11: 17.

40. Faghihi Langroudi $T$, Sheikh $M$, Naderian $M$, Sanei Taheri M, Ashraf-Ganjouei A, Khaheshi I. The association between the pulmonary arterial obstruction index and atrial size in patients with acute pulmonary embolism. $R$ Radiol Res Pract 2019; 2019: 6025931.

41. Oz II, Altinsoy B, Serifoglu I, Sayin R, Buyukuysal MC, Erboy $F$, et al. Evaluation of right atrium-to-right ventricle diameter ratio on computed tomography pulmonary angiography: Prediction of adverse outcome and 30-day mortality. Eur J Radiol 2015; 84(12): 2526-32.

42. Bhave NM, Visovatti SH, Kulick B, Kolias TJ, McLaughlin VV. Right atrial strain is predictive of clinical outcomes and invasive hemodynamic data in group 1 pulmonary arterial hypertension. Int / Cardiovasc Imaging 2017; 33(6): 84755 . 